\title{
LARGE-EDDY/REYNOLDS-AVERAGED NAVIER- STOKES SIMULATION OF SHOCK-TRAIN DEVELOPMENT IN A COIL-LASER DIFFUSER
}

Jack R. Edwards

North Carolina State University

2701 Sullivan Dr. STE 240

Campus BX 7514

Raleigh, NC 27695-7003

6 September 2014

Final Report

APPROVED FOR PUBLIC RELEASE; DISTRIBUTION IS UNLIMITED.

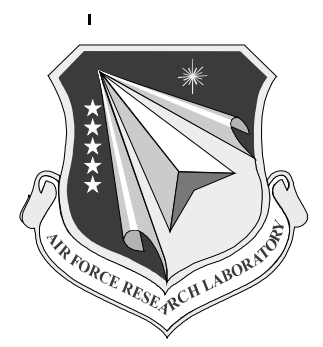
AIR FORCE RESEARCH LABORATORY
Directed Energy
3550 Aberdeen Ave SE
AIR FORCE MATERIEL COMMAND
KIRTLAND AIR FORCE BASE, NM 87117-5776 


\section{NOTICE AND SIGNATURE PAGE}

Using Government drawings, specifications, or other data included in this document for any purpose other than Government procurement does not in any way obligate the U.S. Government. The fact that the Government formulated or supplied the drawings, specifications, or other data does not license the holder or any other person or corporation; or convey any rights or permission to manufacture, use, or sell any patented invention that may relate to them.

This report was cleared for public release by the Air Force Research Laboratory [insert TD site] Public Affairs Office and is available to the general public, including foreign nationals. Copies may be obtained from the Defense Technical Information Center (DTIC) (http://www.dtic.mil).

AFRL-RD-PS-TR-2014-0029 HAS BEEN REVIEWED AND IS APPROVED FOR PUBLICATION IN ACCORDANCE WITH ASSIGNED DISTRIBUTION STATEMENT.

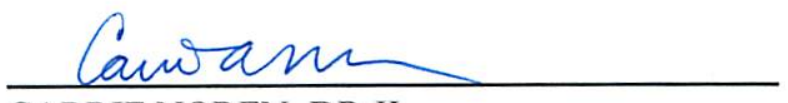

CARRIE NOREN, DR-II

Work Unit Manager

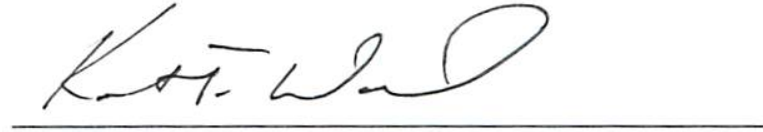

KENTON T. WOOD, DR-IV

Chief, Laser Division

This report is published in the interest of scientific and technical information exchange, and its publication does not constitute the Government's approval or disapproval of its ideas or findings. 


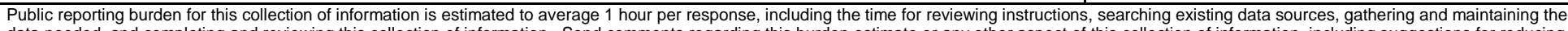

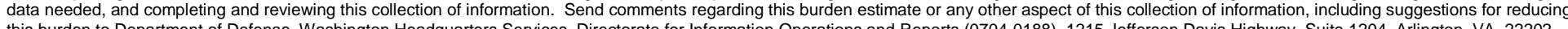

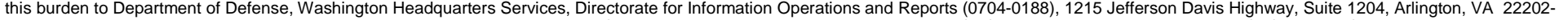

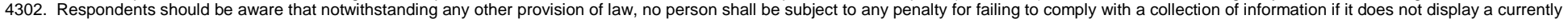
valid OMB control number. PLEASE DO NOT RETURN YOUR FORM TO THE ABOVE ADDRESS.

\begin{tabular}{l|l|l}
\hline 1. REPORT DATE (DD-MM-YYYY) & 2. REPORT TYPE & 3. DATES COVERED (FrOm - To)
\end{tabular}

06/09/2014 $\quad$ Final Report

4. TITLE AND SUBTITLE 1 Januarv 2013- 6 September 2014 5a. CONTRACT NUMBER

FA9451-13-1-0262

Large-Eddy/Reynolds-Averaged Navier-Stokes Simulation of Shock-Train Development in a COIL -Laser Diffuser 5b. GRANT NUMBER

\section{AUTHOR(S)}

Jack R. Edwards

5c. PROGRAM ELEMENT NUMBER 62605F

5d. PROJECT NUMBER

5e. TASK NUMBER

5f. WORK UNIT NUMBER

D05N

\section{PERFORMING ORGANIZATION NAME(S) AND ADDRESS(ES)}

North Carolina State University

8. PERFORMING ORGANIZATION REPORT NUMBER

Department of Mechanical and Aerospace Engineering

Campus Box 7910

North Carolina State University, Raleigh, NC 27695

9. SPONSORING I MONITORING AGENCY NAME(S) AND ADDRESS(ES)

Air Force Research Laboratory

3550 Aberdeen Ave SE

Kirtland AFB, NM 87117-5776

10. SPONSOR/MONITOR'S ACRONYM(S)

AFRL/RDLTS

11. SPONSOR/MONITOR'S REPORT NUMBER(S)

AFRL-RD-PS-TR-2014-0029

12. DISTRIBUTION / AVAILABILITY STATEMENT

Approved for public release: distribution unlimited.

\section{SUPPLEMENTARY NOTES}

Cleared for public release on 3 Nov 2014 ; 377ABW-2014-0866.

\section{ABSTRACT}

This report describes the application of a hybrid large-eddy simulation / Reynolds-averaged Navier-Stokes method to predict shock train formation and reactant mixing in a model Chemical Oxygen Iodine Laser (COIL) unit. The configuration consists of a converging-diverging nozzle, a lasing cavity, and a diffuser. Results have been obtained for several grids and for several back pressures, the variation of which fixes the average shock-train position within the nozzle. Predictions of wall pressure are in reasonable accord with experimental observations for both LES/RANS and RANS model but tend to under-predict the initial rate of pressure increase as the flow encounters the leading edge of the shock train. Though the shock train induces a transition to turbulence as well as local flow separation, the effects of resolved turbulence and unsteady separation do not appear to influence the mixing process in the lasing cavity significantly.

\section{SUBJECT TERMS}

Large-eddy simulation, chemical oxygen iodine lasers, shock trains, Reynolds-averaged Navier-Stokes equations

\begin{tabular}{|l|l|l|c|l|}
\hline \multicolumn{2}{|l|}{ 16. SECURITY CLASSIFICATION OF: } & $\begin{array}{l}\text { 17. LIMITATION } \\
\text { OF ABSTRACT }\end{array}$ & $\begin{array}{l}\text { 18. NUMBER } \\
\text { OF PAGES }\end{array}$ & $\begin{array}{l}\text { 19a. NAME OF RESPONSIBLE PERSON } \\
\text { Carrie Noren }\end{array}$ \\
\cline { 1 - 1 } $\begin{array}{l}\text { a. REPORT } \\
\text { Unclassified }\end{array}$ & $\begin{array}{l}\text { b. ABSTRACT } \\
\text { Unclassified }\end{array}$ & $\begin{array}{l}\text { c. THIS PAGE } \\
\text { Unclassified }\end{array}$ & SAR & $\begin{array}{l}\text { 19b. TELEPHONE NUMBER (include area } \\
\text { code) } \\
505-853-2685\end{array}$ \\
\end{tabular}




\section{TABLE OF CONTENTS}

Section

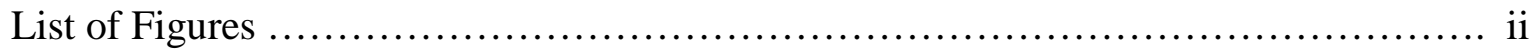

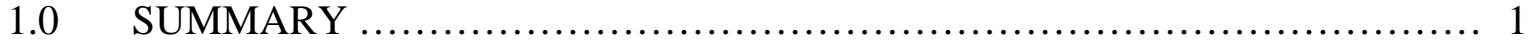

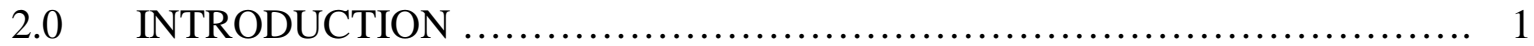

3.0 METHODS, ASSUMPTIONS, AND PROCEDURES …................... 2

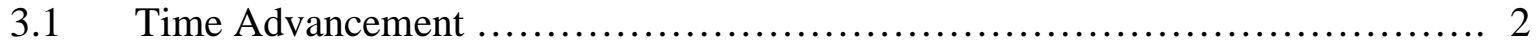

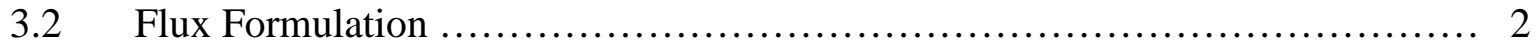

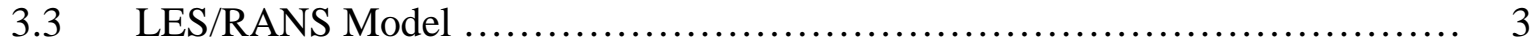

$4.0 \quad$ RESULTS AND DISCUSSION .......................................... 4

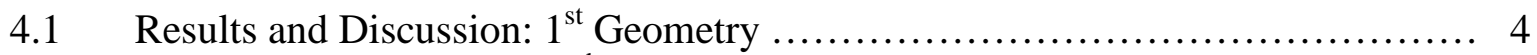

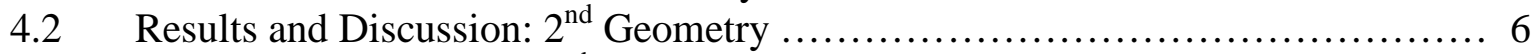

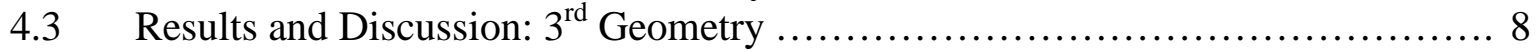

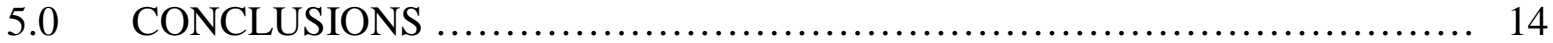

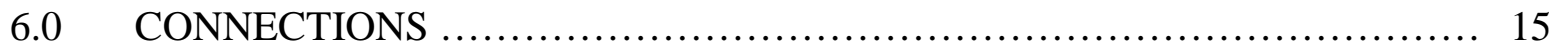

7.0 ACKNOWLEDGEMENTS ............................................... 15

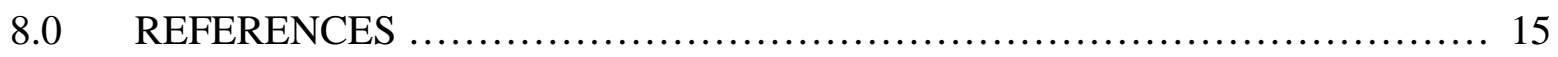

List of Symbols, Abbreviations and Acronyms.................................... 16

Approved for public release; distribution unlimited. 


\section{LIST OF FIGURES}

Figure

$1 \quad$ Mean and rms wall pressure: Geometry $\# 1 \ldots \ldots \ldots \ldots \ldots \ldots \ldots \ldots \ldots \ldots \ldots \ldots$

2 Centerplane Mach number distributions at different time instances:

14.7 Torr back pressure................................................. 5

3 Centerplane Mach number contours: Geometry \#2 …....................... 6

$4 \quad \mathrm{X}$-Y centerplane length-scale ratio from RANS solution: Geometry \#2 ......... 6

$5 \quad \mathrm{X}-\mathrm{Y}$ centerline length-scale ratios: Geometry \#1 vs Geometry \#2 ............... 7

6 Wall pressure distribution (22.8 Torr back pressure; LES/RANS on Geometry

\#2)..................................................................... 7

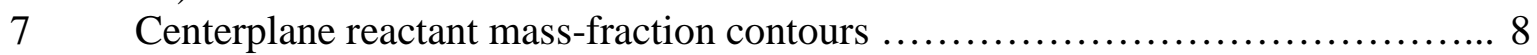

8 Centerplane Mach number contours for flow with 22.8 Torr back pressure.

Top: RANS, Middle: time averaged LES/RANS, Bottom: Instantaneous

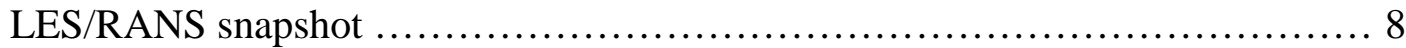

9 Centerplane $\mathrm{N}_{2}$ mass fraction contours for flow with 22.8 Torr back pressure.

Top: RANS, Middle: time averaged LES/RANS, Bottom: Instantaneous

LES/RANS snapshot

10 Centerplane Mach number contours for flow with 14.7 Torr back pressure.

Top: RANS, Middle: time averaged LES/RANS, Bottom: Instantaneous

LES/RANS snapshot ................................................. 10

11 Centerplane $\mathrm{N}_{2}$ mass fraction contours for flow with 14.7 Torr back pressure.

Top: RANS, Middle: time averaged LES/RANS, Bottom: Instantaneous

LES/RANS snapshot................................................ 10

12 Comparison of upper centerline wall pressures for different values of the

back pressure

13 Maximum (top) and minimum (bottom) extent of reversed flow on the

upper wall ............................................................ 12

14 Snapshots of $\mathrm{N}_{2}$ mass fraction iso-surfaces (0.065), colored by pressure ............. 12

15 Instantaneous $\mathrm{N}_{2}$ mass fraction and Mach number profiles in lasing cavity ........ 13

16 Resolved-scale turbulence kinetic energy in the lasing cavity .................... 14

Approved for public release; distribution unlimited. 


\subsection{SUMMARY}

This report describes the application of a hybrid large-eddy simulation / Reynoldsaveraged Navier-Stokes (LES/RANS) turbulence modeling strategy to predict reactant mixing and shock-train propagation within a model Chemical Oxygen Iodine Laser (COIL) unit. The configuration consists of a converging-diverging nozzle, a lasing cavity, and a diffuser. The intent of this investigation is to assess the potential of LES/RANS technology in predicting the possible effects of shock-train motion on the flow within the lasing cavity. Results have been obtained for several grids and for several back pressures, the variation of which fixes the average shock-train position within the nozzle. Predictions of wall pressure are in reasonable accord with experimental observations for both LES/RANS and RANS model but tend to under-predict the initial rate of pressure increase as the flow encounters the leading edge of the shock train. Though the shock train induces a transition to turbulence as well as local flow separation, the effects of resolved turbulence and unsteady separation do not appear to influence the mixing process in the lasing cavity significantly. Moderately unsteady laminar-flow mixing processes dominate in the lasing cavity, providing efficient mixing of reactants without turbulence. This indicates that current diffuser designs may provide sufficient isolation of the lasing process from the pressure recovery process, at least for moderate back pressures.

\subsection{INTRODUCTION}

Chemical Oxygen Iodine Laser (COIL) systems require low pressures for effective operation, and to recover ambient pressure levels, diffuser and ejector technologies are necessary. The design of an effective diffuser system capable of containing the 'shock train' that provides initial pressure recovery involves several considerations. Among these are the need to operate effectively over a range of back pressures and the requirement that the lasing cavity be isolated from the unsteady dynamics of the shock train to improve mixture homogeneity and thereby enhance laser gain. Though nearly laminar-flow conditions may be maintained in the lasing cavity, a transition to turbulence, enhanced by shock-induced amplification of boundarylayer disturbances, will take place in the pressure-recovery section. Local fluctuation intensities, scaling with the shear layer thickness, emerge as a result of turbulent flow, but lower-frequency oscillations also can emerge and can lead to large-scale oscillations of the entire shock-train system. The cause of such oscillations is a matter of debate, even for single shock / boundary layer interactions [1], but the prevailing opinion is that they result from net entrainment of fluid into separation regions at a frequency generally proportional to the mean size of the separatedflow region. Gieseking and Edwards [2] show that the dominant low frequency component of separation-shock unsteadiness is directly correlated with the most probable residence time of fluid within the separated-flow region - an observation that may make it possible to predict unsteady characteristics by extracting residence time distributions from steady calculations. In COIL laser systems, low-momentum regions are found near corners as well as in regions directly affected by shock impingement, and large-scale oscillations of the diffuser shock-train system are indeed observed. It is of interest to understand the causes behind shock-train unsteadiness in these systems and their concomitant influence on the lasing process.

The objective of this research effort is to apply a recently-developed hybrid large-eddy simulation / Reynolds-averaged Navier-Stokes (LES/RANS) turbulence model to simulate

Approved for public release; distribution unlimited. 
shock-train formation in a model COIL nozzle / diffuser. The LES/RANS method, enhanced by low-dissipation numerics, should be capable of capturing the larger scales of turbulent unsteadiness resulting from shock / viscous layer interactions as well as oscillations of the entire shock-train system. Predictions are compared with available experimental data [3], which consists of wall pressure distributions obtained in a representative COIL unit consisting of a converging / diverging nozzle, several injectors, a lasing cavity, and a diffuser. Previous predictions using GASP on a 33 million cell mesh that resolves several injection units have shown a significant sensitivity of the diffuser response to variations in the chosen turbulence model for a given back pressure. [3,4] The remainder of this report describes some details of the numerical methods used to sustain turbulence, the LES/RANS closure model employed in this work, and results from several studies that focus on idealized and realistic COIL nozzle / diffuser systems.

\subsection{METHODS, ASSUMPTIONS, AND PROCEDURES}

\subsection{Time Advancement}

North Carolina State University's (NCSU) REACTMB flow solver is used in the present effort. REACTMB solves the Navier-Stokes equations governing a multi-component mixture of gases on simply-connected, multi-block structured meshes using finite-volume methods. REACTMB is designed for use on massively-parallel computers and uses MPI for message-passing. Large structured meshes are decomposed into a number of smaller blocks, which are then partitioned over the number of requested cores using a simple divide-and-conquer strategy. REACTMB discretizes the Navier-Stokes system in time using a Crank-Nicholson approach:

$$
\Omega \frac{U^{n+1, k}-U^{n}}{\Delta t}+\frac{1}{2}(1+\theta) R\left(V^{n+1, k}\right)+\frac{1}{2}(1-\theta) R\left(V^{n}\right)=0
$$

where $\Omega$ is the cell volume, $\Delta t$ is the time step. $U$ is the vector of conserved variables, and $R$ is the residual vector. The function $\theta$ is defined as

$$
\theta=\frac{1}{2}\left(1-\tanh \left(\frac{d-d_{t}}{\Delta d}\right)\right), \quad d_{t}=1 \times 10^{-4} \mathrm{~m}, \Delta d=0.2 d_{t}
$$

Here, $d$ is the distance to the nearest solid surface. The function $\theta$ switches the time discretization from Crank-Nicholson to Euler implicit for mesh cells essentially within the laminar sub-layer. Some loss of temporal accuracy results, but this approach is necessary to suppress oscillations in the pressure and transverse-velocity fields for mesh cells with a very high aspect ratio. The matrix system that results from linearizing (1) is solved approximately using a block incomplete lower-upper (ILU) factorization method, and the system is converged to a prescribed tolerance over a sequence of sub-iterations. Jacobian matrix elements are stored over the number of blocks mapped to a particular processor, allowing the "freezing" of the matrix elements and their factorization over the duration of the sub-iterations. This reduces the computational workload significantly.

\subsection{Flux Formulation}

To sustain turbulence, it is necessary to reduce numerical dissipation significantly. The strategy employed in REACTMB combines a variant of the Piecewise Parabolic Method [5] with a fourth-order central difference scheme. Edwards's low diffusion flux-splitting scheme (LDFSS)

Approved for public release; distribution unlimited. 
[6] is used as the Riemann solver. The primitive-variable vector $W=\left[p_{s}, u, v, w, T, k, \omega\right]^{T}$ is used in the reconstruction. The initial step in the PPM reconstruction sets left-and right states to

$$
W_{L, i+1 / 2}^{A}=W_{R, i+1 / 2}^{A}=\frac{7}{12}\left(W_{i}+W_{i+1}\right)-\frac{1}{12}\left(W_{i+2}-W_{i-1}\right)
$$

which yields a fourth-order central difference approximation on uniform meshes. Monotonicity is enforced by a cell-by-cell resetting of left and right states [5], leading to final left- and rightstate values (superscript ' $M$ ') that are different from the averaged ones (superscript 'A'). The amount of numerical dissipation added at a cell interface is proportional to the difference in leftand right-state values. While enforcing monotonicity helps in shock-capturing, it compromises the ability of the scheme to resolve small-scale turbulent structures. One means of alleviating this problem is to blend the averaged values (3) with the monotonicity-preserving values, so that the former is used in regions of high vorticity (boundary layers, shear layers) and the latter is used in more 'inviscid' regions, where strong shocks might be present. A function due to Ducros, et al. [7], defined at a mesh cell as

$$
f=\frac{(\nabla \cdot \vec{V})^{2}}{(\nabla \cdot \vec{V})^{2}+|\omega|^{2}+\varepsilon^{2}}, \quad \varepsilon=1 \times 10^{-8} V_{\infty} / \max (\overline{\Delta x}, \overline{\Delta y}, \overline{\Delta z}),
$$

is used for this purpose. Here, the divergence of velocity is compared with the vorticity value. If the latter is much larger (in shear and boundary layers, for example), the function moves toward zero, and in free-stream regions near shocks, the function approaches one. At a particular cell interface $i+1 / 2$, we use the function as follows:

$$
\begin{aligned}
& W_{L, i+1 / 2}=W_{L, i+1 / 2}^{A}+\max \left(f_{i}, f_{i+1}, 0.1\right)\left(W_{L, i+1 / 2}^{M}-W_{L, i+1 / 2}^{A}\right) \\
& W_{R, i+1 / 2}=W_{R, i+1 / 2}^{A}+\max \left(f_{i}, f_{i+1}, 0.1\right)\left(W_{R, i+1 / 2}^{M}-W_{R, i+1 / 2}^{A}\right)
\end{aligned}
$$

This scheme, denoted as LD-PPM for low-dissipation PPM, is used for all LES/RANS calculations presented in this paper. Viscous and diffusive terms appearing in the equation system are discretized using second-order central differences.

\subsection{LES/RANS Model}

NCSU's hybrid LES/RANS methodology [2,8] is used as the baseline for the current work. In the LES/RANS model, the effects of anisotropic near-wall eddies are modeled using RANS concepts (Menter's $k-\omega$ baseline model), whereas the larger turbulent eddies away from solid surfaces are captured using a large-eddy simulation method. The shift between the closure models is facilitated by modifying the eddy viscosity field according to

$$
\mu_{t}=\rho\left[(1-\Gamma) v_{t, s g s}+\Gamma \frac{k}{\omega}\right], \Gamma=\frac{1}{2}\left(1-\tanh \left[15\left(\frac{1}{\lambda_{N}^{2}}-1\right)\right]\right)
$$

Here, $\Gamma$ is a time-dependent blending function that connects the RANS and LES branches and the quantity $\lambda_{N}$ is a ratio of outer- to inner-layer turbulence length scales, with the former calculated using both ensemble-averaged and instantaneous turbulence data. Specific definitions are as follows:

$$
\lambda_{N}=g\left(l_{\text {outer }}\right) l_{\text {outer }} / l_{\text {inner }}, \quad g\left(l_{\text {outer }}\right)=\min \left[D_{1}, \max \left(1, D_{2} \frac{\Delta_{\max }}{l_{\text {outer }}} \sqrt{\frac{\bar{\omega}}{\omega}}\right)\right]
$$

where

Approved for public release; distribution unlimited. 


$$
l_{\text {outer }}=C_{N} \sqrt{\frac{10 v \bar{\omega}+\bar{k}+\bar{k}_{R}}{C_{\mu}^{1 / 2} \bar{\omega} \omega}}, \quad l_{\text {inner }}=\kappa d
$$

The model constants $D_{1}$ and $D_{2}$ are assigned values of 10 and 0.5 , based on calibrations for flatplate boundary layers. The mesh scale $\Delta_{\max }$ is taken to be the maximum spacing over all three coordinate directions. This form serves to shift the closure to unsteady RANS when there is no possibility of resolving the largest turbulence length scales. If the maximum mesh scale is selected as the outer-layer scale consistently, then the LES/RANS model behaves similarly to detached-eddy simulation, serving primarily to isolate turbulent boundary layers from massivelyseparated regions. The quantity $\bar{k}_{R}$ is the resolved turbulence kinetic energy, calculated via ensemble-averaging as

$$
\bar{\rho} \bar{k}_{R}=\frac{1}{2}\left(\overline{\rho u_{k} u_{k}}-\frac{\overline{\rho u}_{k} \overline{\rho u_{k}}}{\bar{\rho}}\right)
$$

The quantities $\bar{k}$ and $\bar{\omega}$ are ensemble-averages of the modeled turbulence kinetic energy and specific dissipation rate variables, which are obtained from Menter's model. The use of ensemble-averaged as well as instantaneous data allows the RANS-to-LES transition location to 'float' about a time-mean location that is a function of the ensemble-averaged state of the boundary layer. This enables the blending function to respond more directly to large changes in the turbulence length scales that can result from shock interactions. Ensemble-averages are currently calculated using an exponentially-weighted moving average: $\bar{Q}^{n}=(1-A) \bar{Q}^{n-1}+A Q^{n}$ with $A=\Delta t / \tau$. The time scale $\tau$ is defined as follows for the cases considered herein:

$$
\begin{aligned}
\tau & =\min \left(t, t_{\text {res }}\right), t<4 t_{\text {res }} \\
& =t-3 t_{\text {res }}, t \geq 4 t_{\text {res }}
\end{aligned}
$$

where $\tau_{\text {res }}=L / u_{\infty}$ is defined in terms of the length of the domain $L$ and the free-stream velocity $u_{\infty}$ This form assumes that a statistically-stationary state will emerge after about four residence times

\subsection{RESULTS AND DISCUSSION}

This model has been applied to three nozzle / diffuser geometries representative of COIL lasing units. The first contains $\sim 75$ million cells but neglects injector units and contains some geometric simplifications. The second contains $\sim 70$ million cells, incorporates several iodine injector units, and corresponds geometrically to an experiment described in [3]. The third is equivalent to the second but with many more cells (228 million cells in total) added to resolve eddy dynamics better.

\subsection{Results and Discussion: $1^{\text {st }}$ geometry}

Wall pressure distributions for two back pressures (14.7 Torr and 26.4 Torr) for the first geometry are shown in Figure 1, as are wall pressure standard deviation distributions, a measure of shock-train unsteadiness.

Approved for public release; distribution unlimited. 


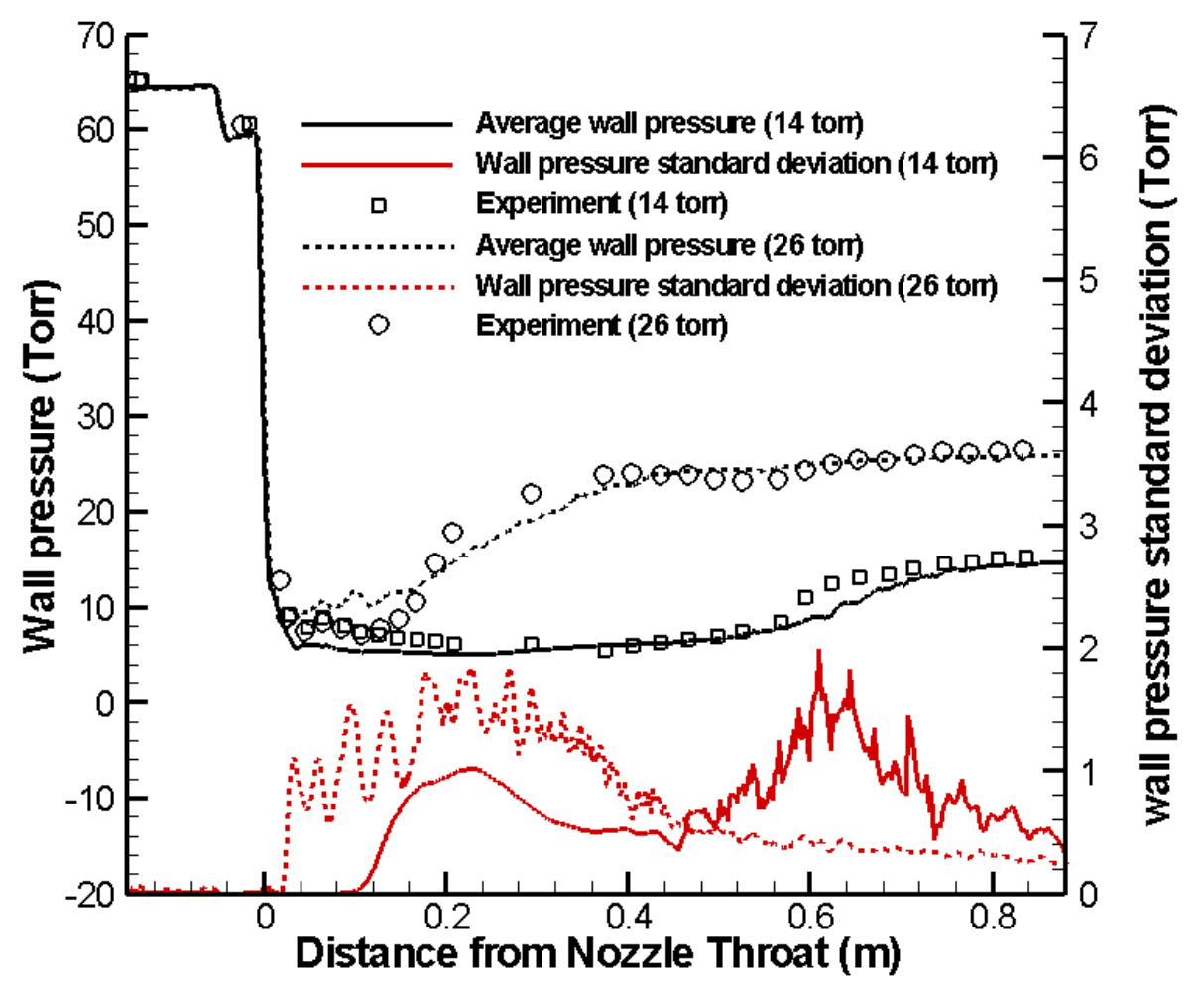

Figure 1: Mean and rms wall pressure: Geometry \#1

Agreement with experiment for mean pressures is fair due to the geometric simplifications employed in the first geometry, while the wall-pressure standard-deviation distributions show the impact of shock-train unsteadiness on the flow in the lasing cavity as well as in the diffuser section.
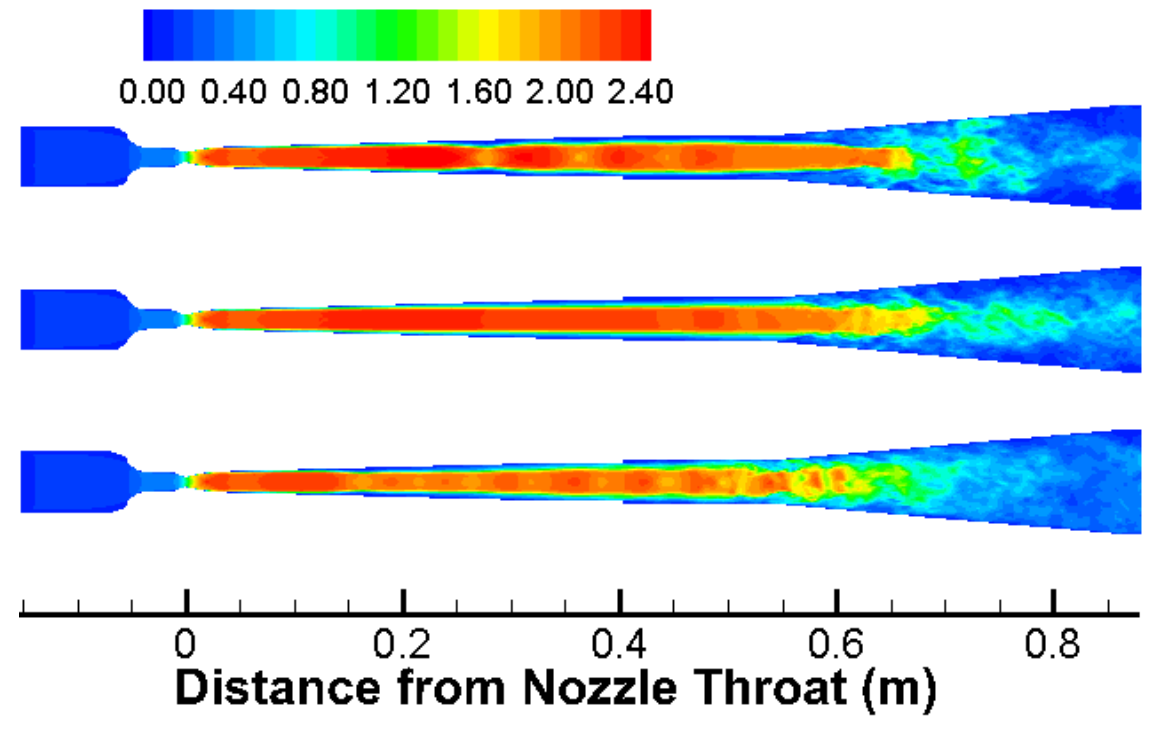

Figure 2: Centerplane Mach number distributions at different time instances: 14.7 Torr back pressure 
Figure 2 shows centerplane snapshots of the shock train and its motion for the 14.7 Torr back pressure. Animations of the pressure signal and the 'footprints' of wall separation regions reveal that regions of reversed flow, located primarily in the corner and sidewall regions, enlarge and shrink in response to shock train motion, providing a path for disturbances to propagate upstream to the lasing cavity.

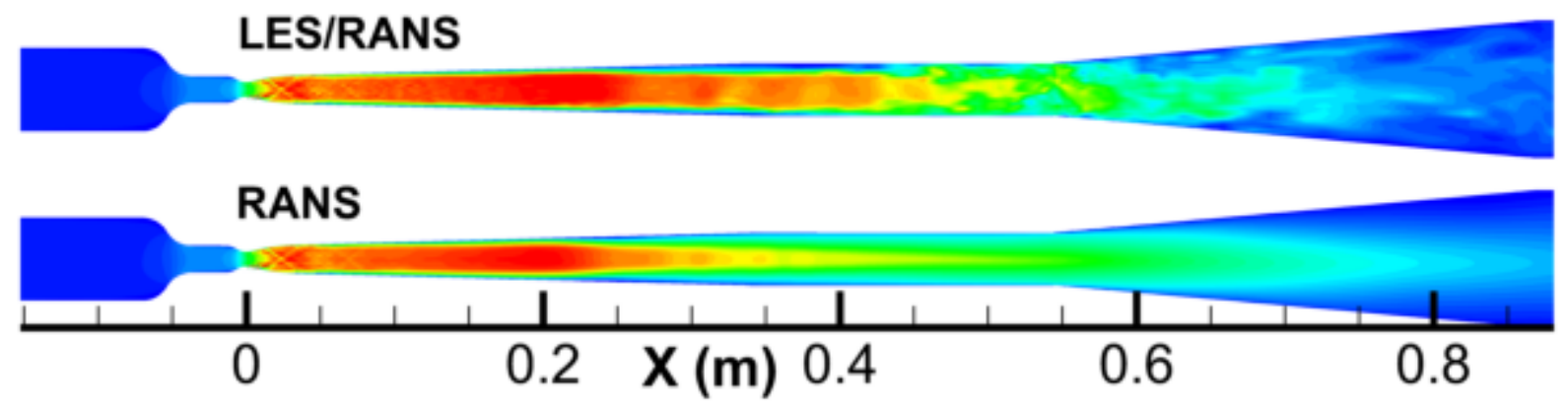

Figure 3: Centerplane Mach number contours: Geometry \#2

\subsection{Results and Discussion: $2^{\text {nd }}$ geometry}

Results from simulations of shock-train development within the second geometry at a back pressure of 22.8 Torr are shown in Figures 3-7. Figure 3 shows centerplane Mach number contours for two cases: a steady RANS simulation and a time-dependent LES/RANS simulation. Some eddy content in the diffuser is noted, but the structures appear to be too large, indicating that the mesh is too coarse in this region.

(Turb. Length)/dx: $\quad 0 \quad 0.20 .40 .60 .8 \quad 1 \quad 1.21 .41 .61 .8 \quad 2$
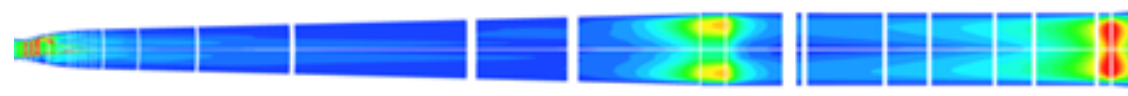

Figure 4: $\mathrm{X}$-Y centerplane length-scale ratio from RANS solution: Geometry \#2

Figure 4 plots the ratio of the modeled turbulence length scale from the RANS solution to the maximum of the grid dimension: $\quad$ ratio $=\frac{\sqrt{k} /\left[\beta^{* 1 / 4} \omega\right]}{\max (\Delta x, \Delta y, \Delta z)}$. Adequate resolution would imply that this quantity is greater than one in regions of significant turbulence activity. Figure 5 compares this ratio along the centerline of the X-Y plane with that extracted from the Geometry \#1 RANS solution. In the diffuser section, the ratio is always greater than one for Geometry \#1 while generally less than one for Geometry \#2. This indicates that the LES/RANS calculation for Geometry \#2 is under-resolved in this region and in other locations. As a possible consequence and as shown in Figure 6, the wall pressure prediction is very poor for this case. Figure 7 shows some evidence of unsteadiness of the mixing plume in the lasing cavity. This may arise from natural instabilities that possibly are amplified by external forcing generated from shock-train motion.

Approved for public release; distribution unlimited. 


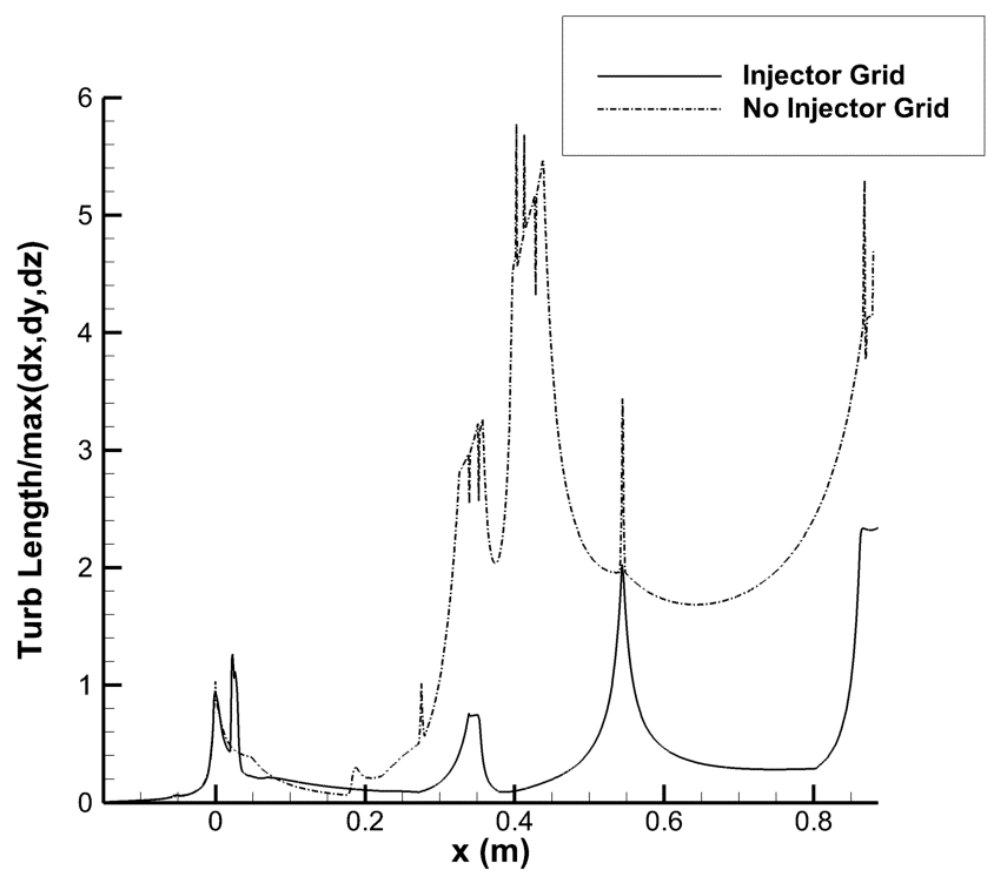

Figure 5: $X-Y$ centerline length-scale ratios:

Geometry \#1 vs Geometry \#2

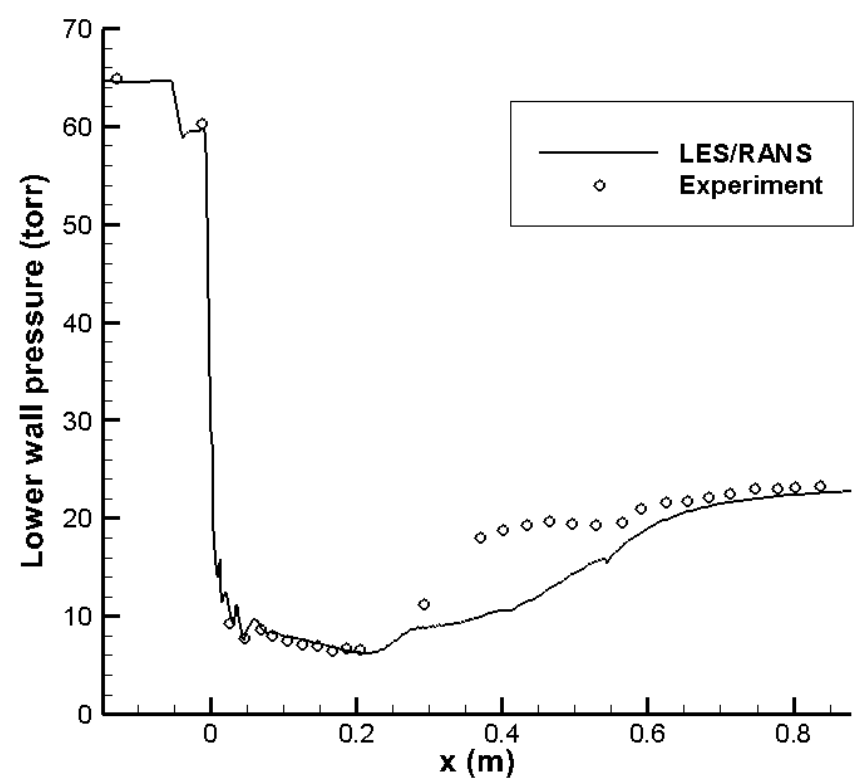

Figure 6: Wall pressure distribution (22.8 Torr back pressure; LES/RANS on Geometry \#2)

Approved for public release; distribution unlimited. 


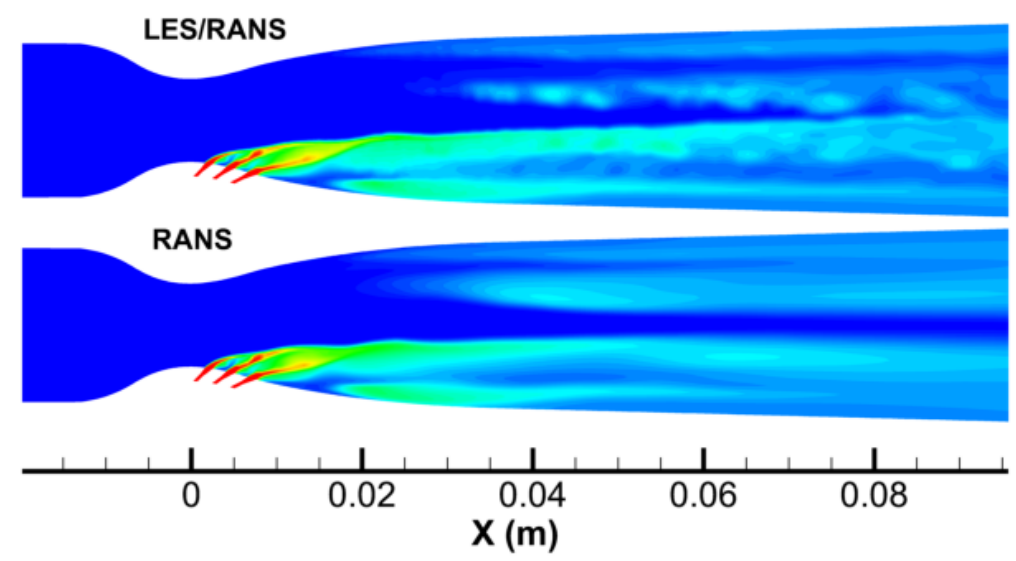

Figure 7: Centerplane reactant mass-fraction

contours

\subsection{Results and Discussion: $3^{\text {rd }}$ geometry}

Based on the results shown above, a new mesh was generated that maintains good resolution in the diffuser section while resolving all injector ports. The mesh contains $\sim 229 \mathrm{M}$ cells partitioned over 17676 blocks. The remaining results were obtained on this mesh. Two cases have been considered, one with a 22.8 Torr back pressure and the other with a 14.7 Torr backpressure.
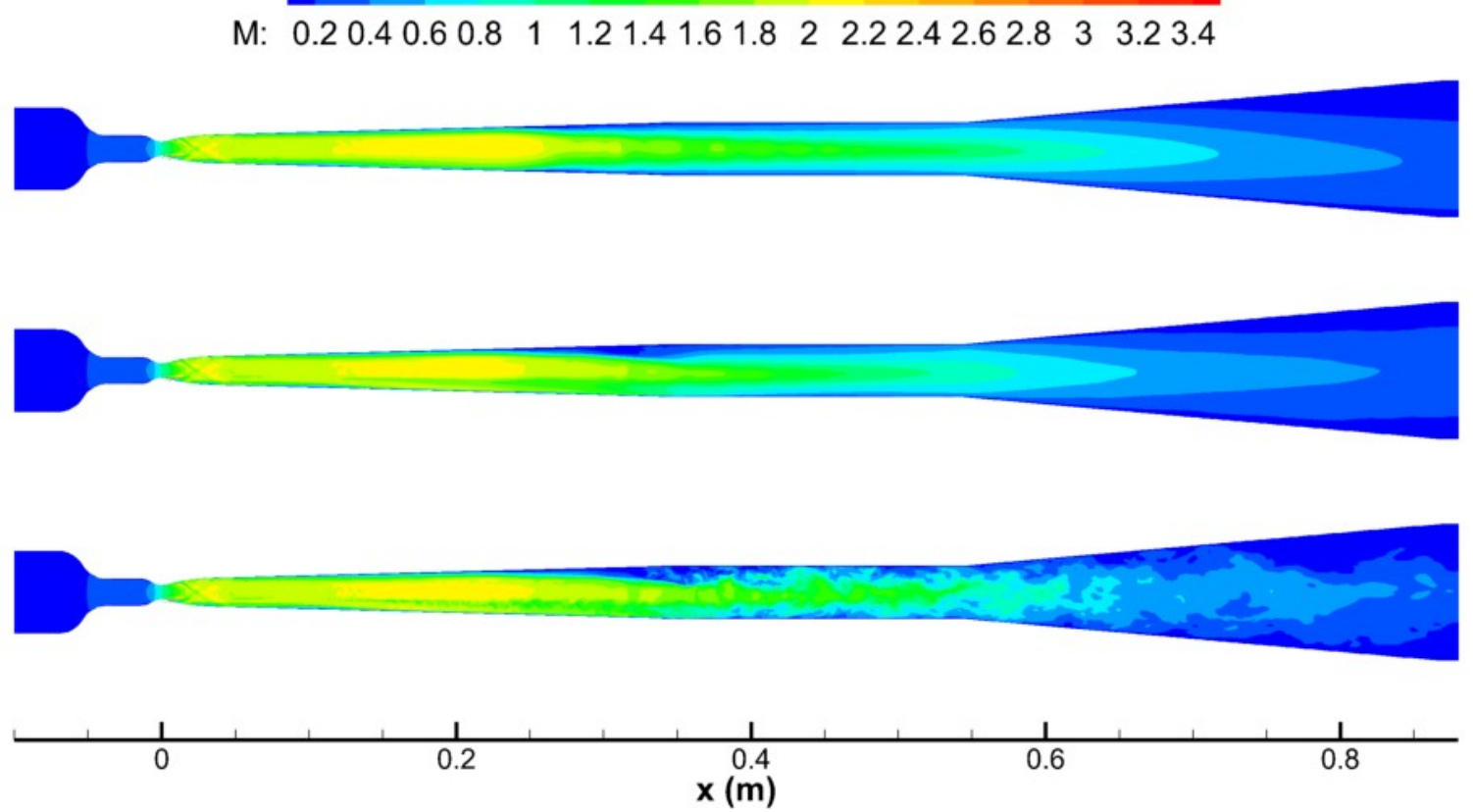

Figure 8: Centerplane Mach number contours for flow with 22.8 Torr back pressure. Top: RANS, Middle: time averaged LES/RANS, Bottom: Instantaneous LES/RANS snapshot 
To initialize the LES/RANS calculations, the two cases were run to convergence using the Menter SST RANS turbulence closure The LES/RANS simulation with 22.8 Torr back pressure was performed using a timestep of 1.5e-7 seconds and progressed for 0.0135 seconds, or approximately nine flow residence times through the nozzle and diffuser sections. Timeaveraged statistics were collected for the last five flow-through times. The simulation with 14.7 Torr back pressure was performed using the same timestep over 0.082 seconds or approximately eight flow residence times, with statistics gathered over the last three flow residence times, which is not yet enough for statistical convergence. Both cases displayed long-period oscillations in the flow resulting in continued fluctuations in the mass flow rates through the cavity - the discrepancy between inflow and outflow mass fluxes reached $2 \%$ in the 22.8 Torr case and as high as $7 \%$ in the 14.7 Torr case.
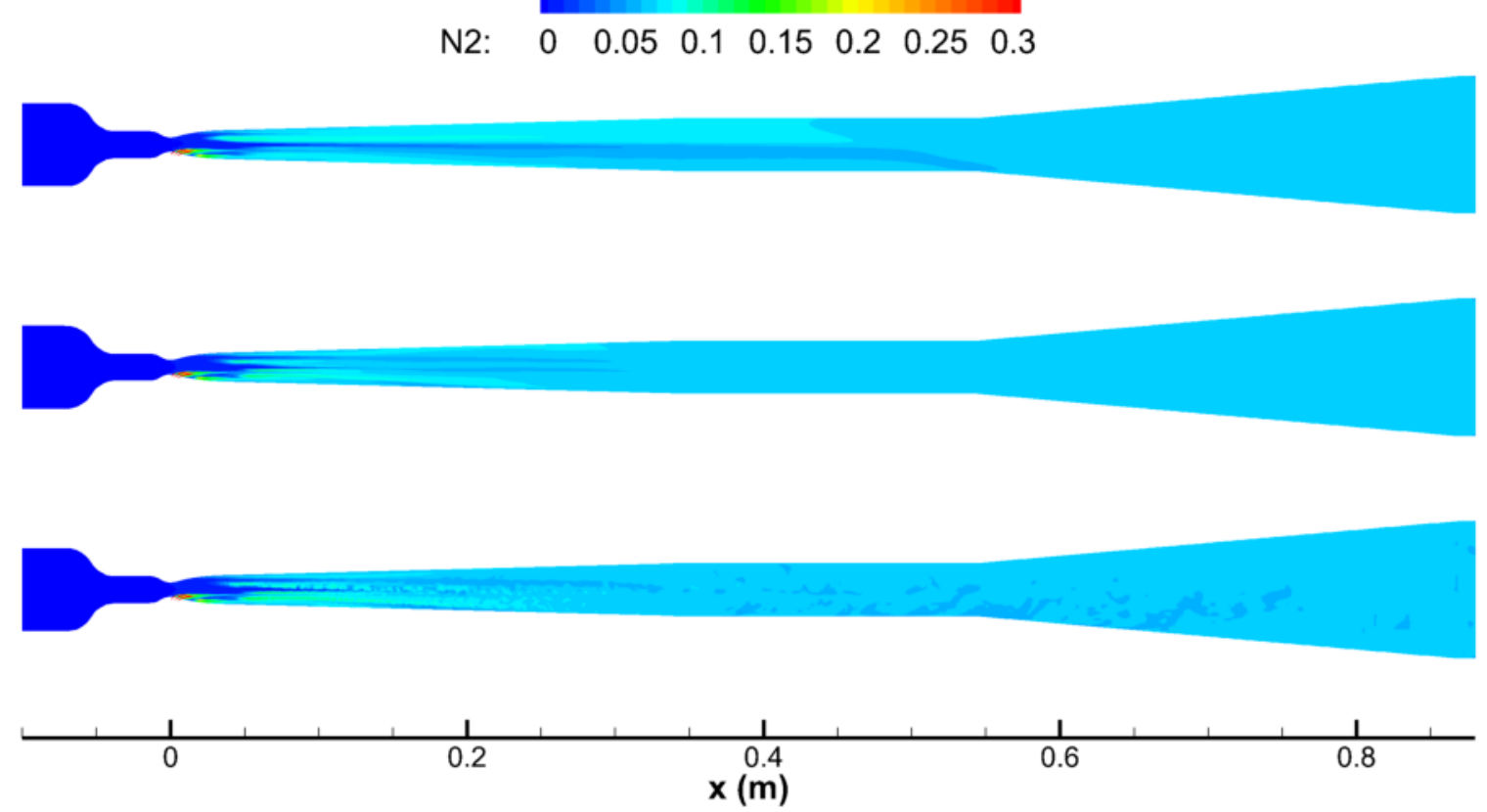

Figure 9: Centerplane $N_{2}$ mass fraction contours for flow with 22.8 Torr back pressure. Top: RANS, Middle: time averaged LES/RANS, Bottom: Instantaneous LES/RANS snapshot

Figures 8-9 compare the centerplane Mach number and $\mathrm{N}_{2}$ mass fraction contours from the RANS, instantaneous LES/RANS, and time-averaged LES/RANS data for the 22.8 Torr back pressure case. The overall structure of the flow for this case can be seen: a series of bow shocks due to the injectors help disperse the injected gas, but otherwise the flow in the nozzle remains supersonic and largely coherent. The main shock train forms around 0.25 meters downstream of the throat, about $15 \mathrm{~cm}$ upstream of the supersonic diffuser. At this point, the core flow decelerates and large-scale turbulence triggered by the shock-boundary layer interaction is observed in the LES/RANS snapshot. A feature seen in the LES/RANS but not the RANS data is the large separation bubble on the upper wall at the start of the shock train. It is clear from comparison of the instantaneous and time-averaged data that the separated region is a transient feature, but its residence time is long enough to affect the average.

Approved for public release; distribution unlimited. 

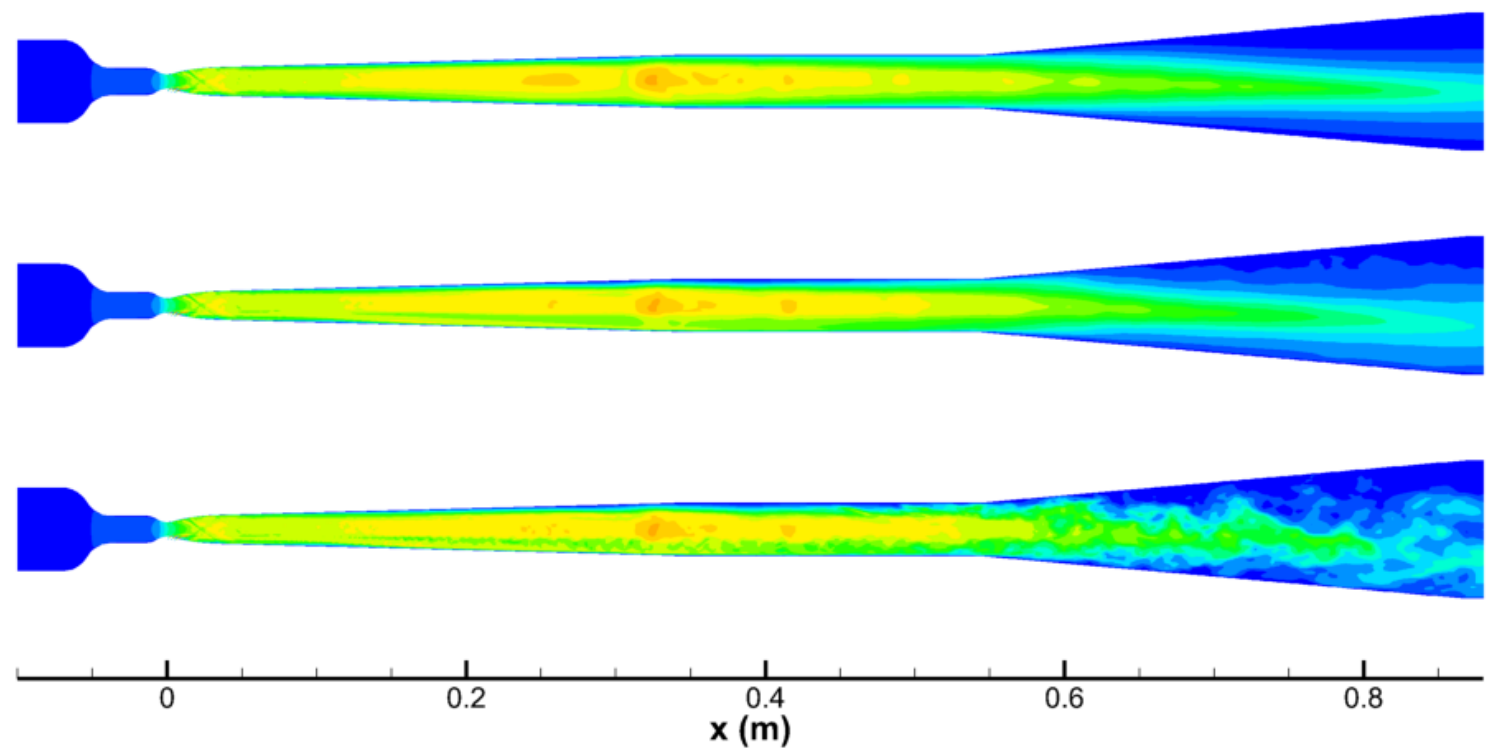

Figure 10: Centerplane Mach number contours for flow with 14.7 Torr back pressure. Top: RANS, Middle: time averaged LES/RANS, Bottom: Instantaneous LES/RANS snapshot
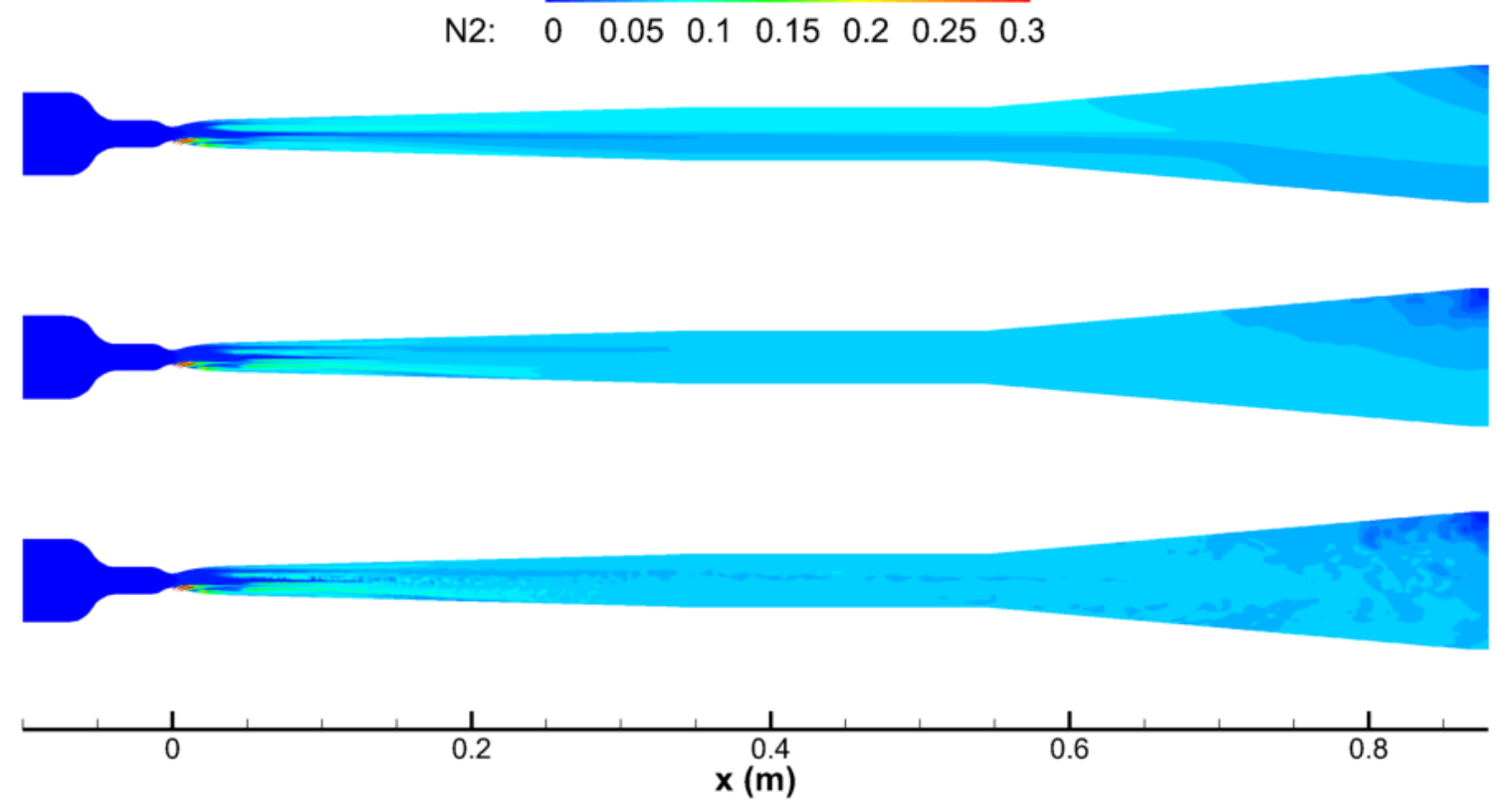

Figure 11: Centerplane $\mathrm{N}_{2}$ mass fraction contours for flow with 14.7 Torr back pressure. Top: RANS, Middle: time averaged LES/RANS, Bottom: Instantaneous LES/RANS snapshot

The 14.7 Torr back pressure case (Figures 10-11) shows similar upstream behavior but the back pressure does not propagate through the supersonic diffuser, and consequently the shock train is 
more gradual and comparatively far downstream. In fact the core flow remains supersonic as it enters the subsonic diffuser, and large-scale turbulence is not observed until that point, about 60 $\mathrm{cm}$ downstream of the nozzle. There appears to be a slight thickening of the boundary layer on the upper wall and a downward deflection in the flow, but it is not as severe as in the higher back pressure case and does not disrupt the flow through the supersonic diffuser section.

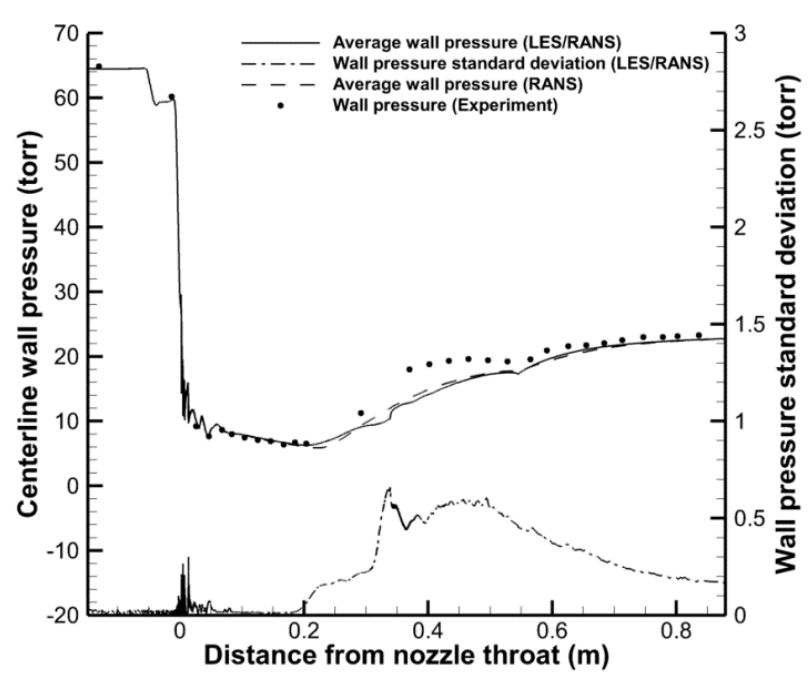

a. 22.8 Torr back pressure

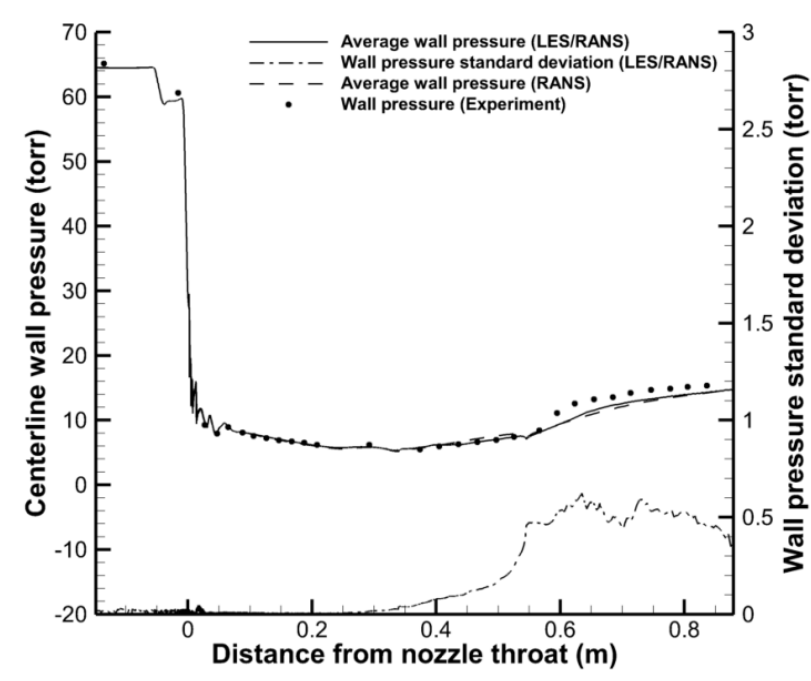

b. 14.7 Torr back pressure

\section{Figure 12: Comparison of upper centerline wall pressures for different values of the back pressure}

A comparison of the computed upper wall pressures with experimental data from Noren, et al (3) (Figure 12) shows that in both cases the RANS and LES/RANS simulation are accurately able to place the location of the pressure rise associated with the shock train. However, in the 22.8 Torr case the predicted pressure recovery in the supersonic diffuser is slower than it is in the experiment, for both the RANS and LES/RANS simulations. The slow pressure rise is also seen, albeit to a lesser extent, in the 14.7 Torr case. This suggests an under-prediction of the boundary layer thickening due perhaps to insufficient mixing with the free-stream, which will be examined later. Overall, the predictions from the RANS and LES/RANS simulations are quite similar, barring a pressure dip about $35 \mathrm{~cm}$ from the nozzle in the LES/RANS data for the 22.8 Torr case. This is associated with the transient separation bubble noted earlier and is confirmed by the spike in the pressure variance in that location. The standard deviation of wall pressure in both cases signifies high levels of unsteadiness within the shock train itself, but the unsteadiness is much less in the lasing cavity downstream of the injection region. Figure 13 shows streamwise velocity snapshots at the top wall in the 22.8 Torr case at points where the shock train is at its maximum and minimum upstream locations. The blue and green areas show where the flow has detached. While there is variation in the overall size of the regions of reversed flow, the back end of the shock appears to remain mostly stationary, with reversed flow at the corners reaching back to $21 \mathrm{~cm}$ downstream of the throat. These persistent corner regions likely provide the pathway for the upstream pressure propagation into the lasing cavity. The band of reversed flow 
on the sidewalls $26 \mathrm{~cm}$ downstream of the throat is due to a slight expansion in the channel at the start of the diffuser.
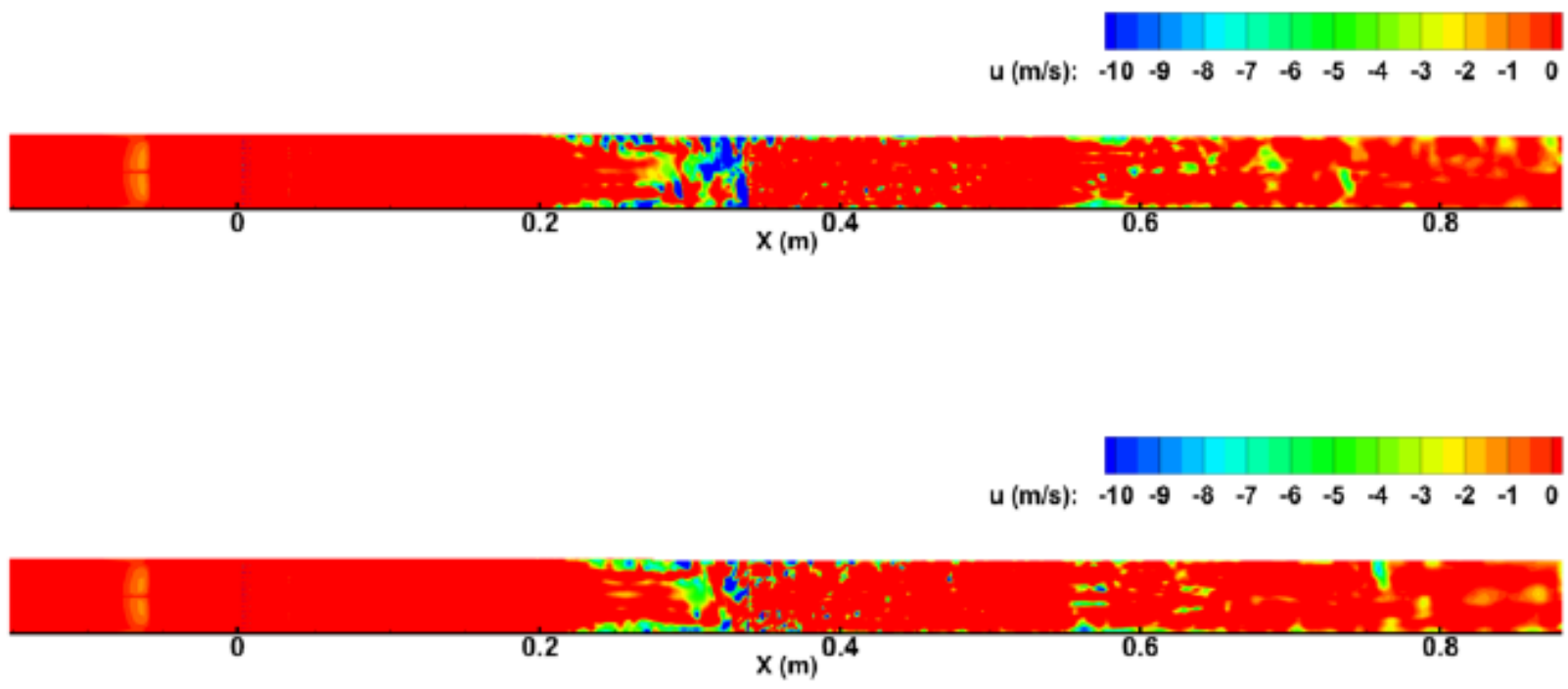

Figure 13: Maximum (top) and minimum (bottom) extent of reversed flow on the upper wall for 22.8 Torr case

A key question in the understanding of this flow regime is the level of interaction between the freestream and boundary layer near the shock train. Figure 14 shows snapshots of the injected $\mathrm{N}_{2}$ isosurface in the lasing cavity for the 22.8 Torr and 14.7 Torr cases, providing a visualization of the core flow. The individual injectant plumes appear to stay coherent far downstream of the injectant location. Structural changes due to the interaction of the shock train with the plumes begin to occur at $\mathrm{X}=25 \mathrm{~cm}$ for the 22.8 Torr case.

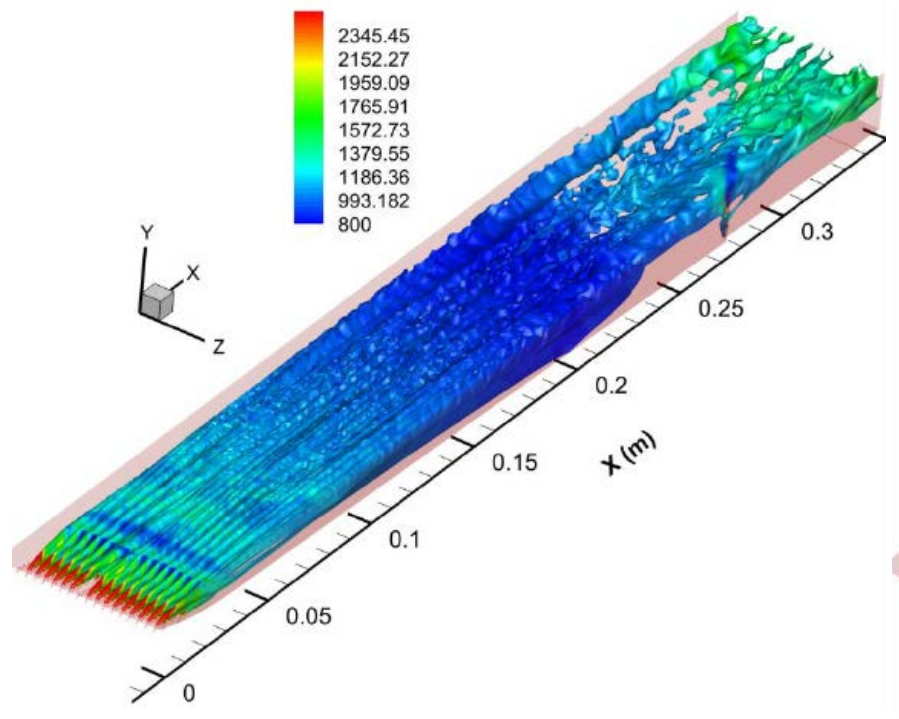

a. 22.8 Torr back pressure

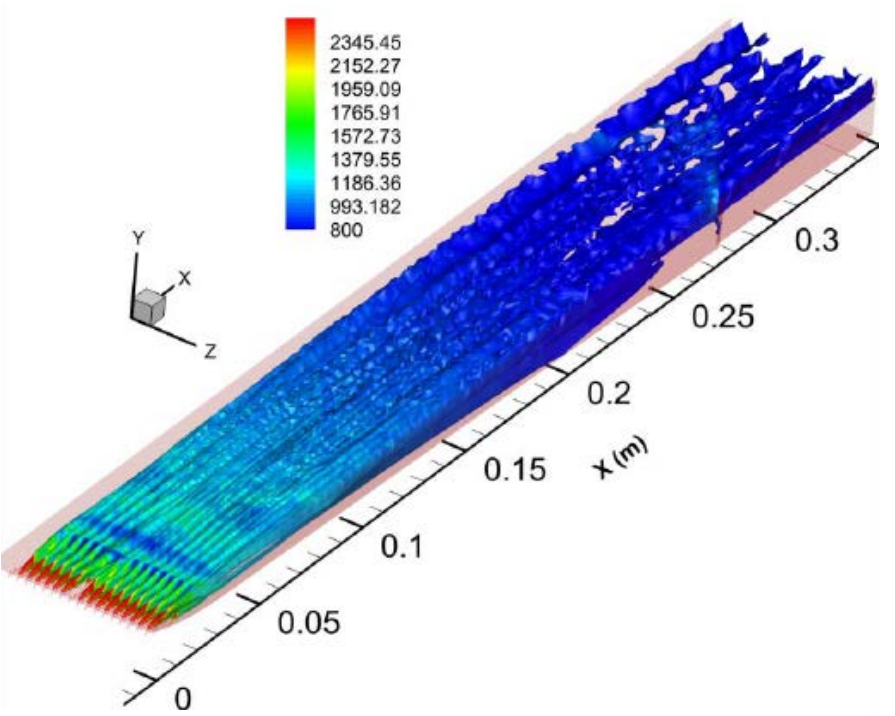

b. 14.7 Torr back pressure

Figure 14: Snapshots of $\mathrm{N}_{2}$ mass fraction iso-surfaces $(0.065)$, colored by pressure

Approved for public release; distribution unlimited. 
As the shock train is downstream of the lasing cavity in the 14.7 Torr back-pressure case, no such changes are evident. Eddies in each jet are likely formed by Kelvin-Helmholtz instability, which could be enhanced by the oblique shocks immediately downstream of the injectors. Cross-flow contours of $\mathrm{N}_{2}$ mass fraction for the 22.8 Torr case (Figure 15) indicate that the actions of the eddies are sufficient to almost fully mix the flow by the time it reaches the supersonic diffuser. Similar results (not shown) are present for the 14.7 Torr case. Figure 15 also shows the instantaneous Mach number in the cavity.

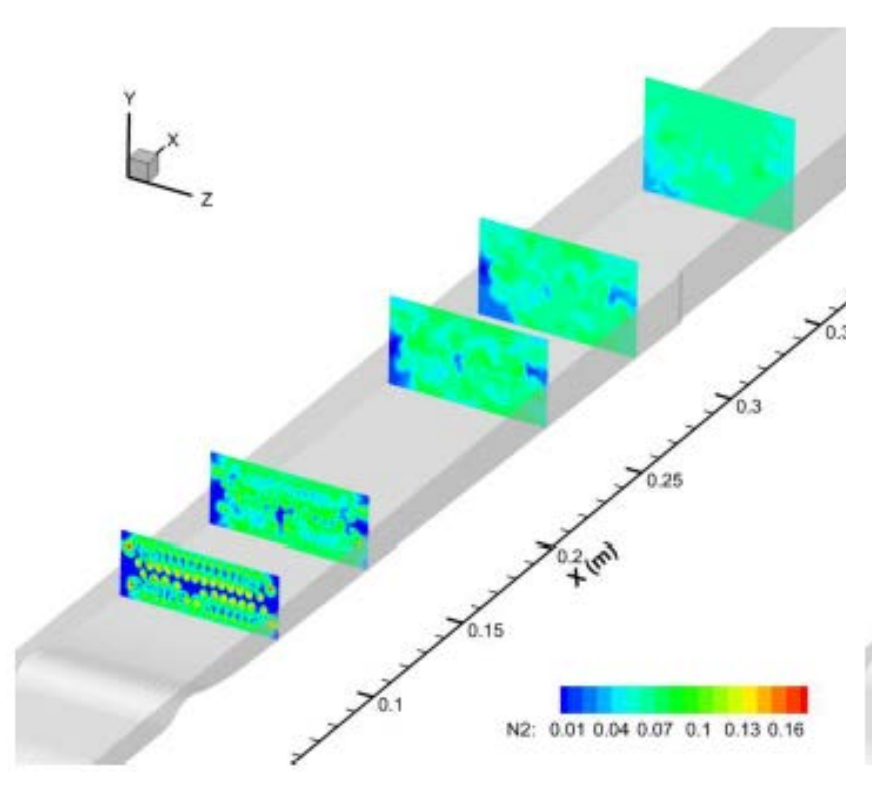

a. $\mathbf{N}_{2}$ mass fraction

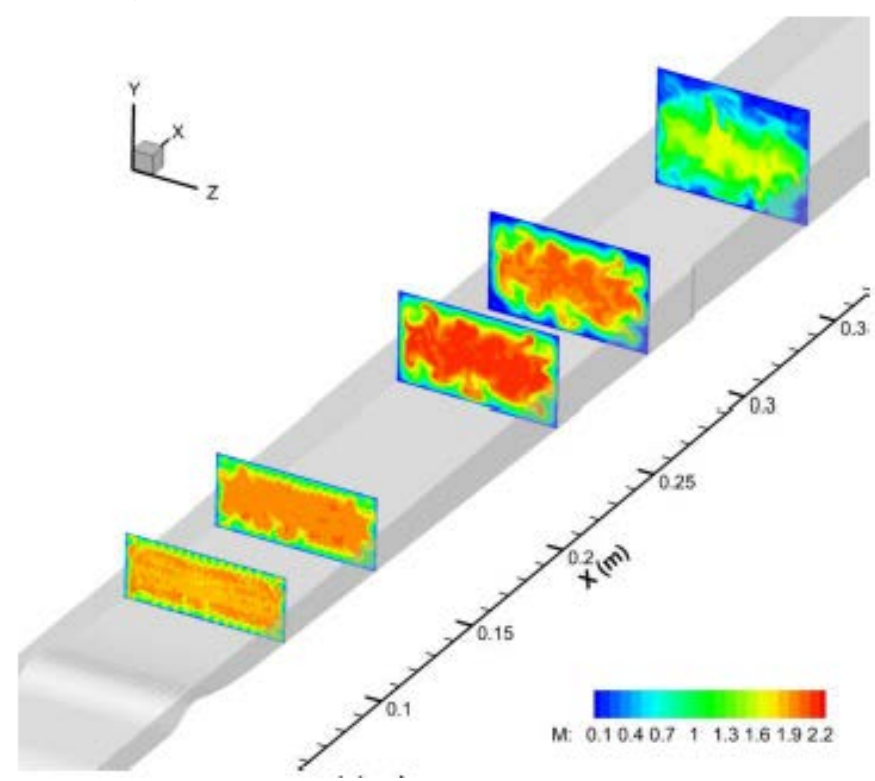

b. Mach number

Figure 15: Instantaneous $\mathrm{N}_{2}$ mass fraction and Mach number profiles in lasing cavity

Boundary layer growth in the upstream section of the cavity is slow, and the main interaction between the boundary layer and free stream appears to be the formation of persistent vortices at the corners which entrain some slow-moving gas into the center of the flow. However, significant boundary layer thickening only occurs after the first oblique shock, seen in the fourth downstream contour. After this, the supersonic core flow rapidly decelerates and the visible flow structures de-cohere. The resolved turbulence kinetic energy, plotted in Figure 16 for both backpressure cases, shows that there is little to no turbulence production in the freestream, which is expected given the low Reynolds numbers involved (the present case has a Reynolds number of approximately 40000 based on the nozzle length). Turbulence energy is only present close to the wall and is not significantly mixed by the free-stream eddies, even at the corners. Interaction with the shock train causes increased turbulence production, especially within the separated flow region at the top wall, but this energy dissipates farther into the shock train. In the farthest downstream contour we can see that the concentration of turbulence energy remains very close to the wall with a limited amount mixed into the core flow eddies. This energy concentration causes a continued thinning of the boundary layer, explaining the overly slow predicted wall pressure rise in the supersonic diffuser. 


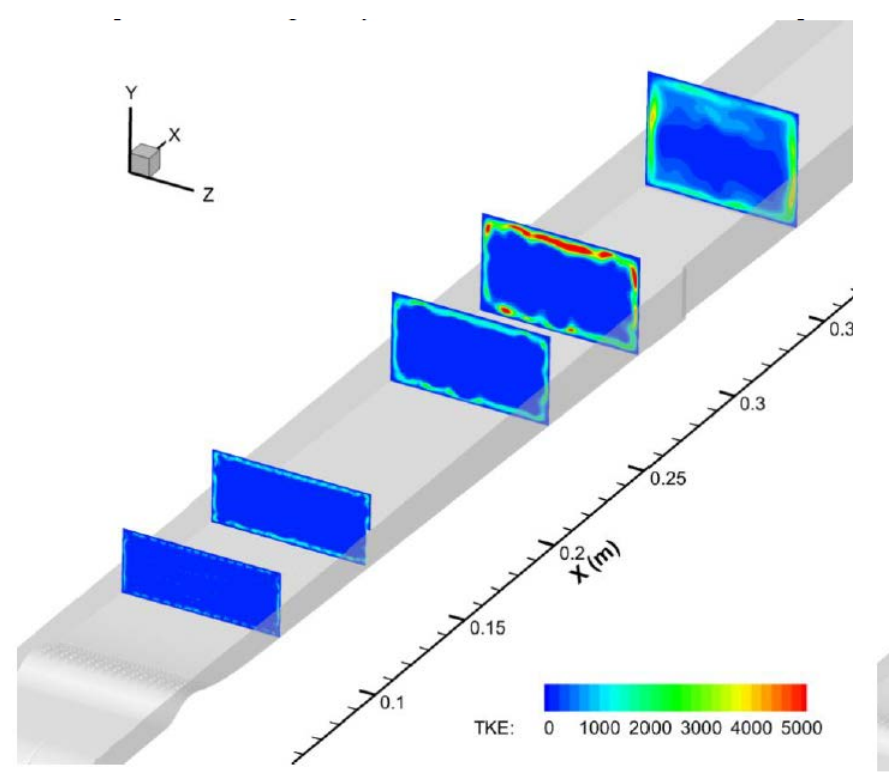

a. $\mathbf{N}_{2}$ mass fraction

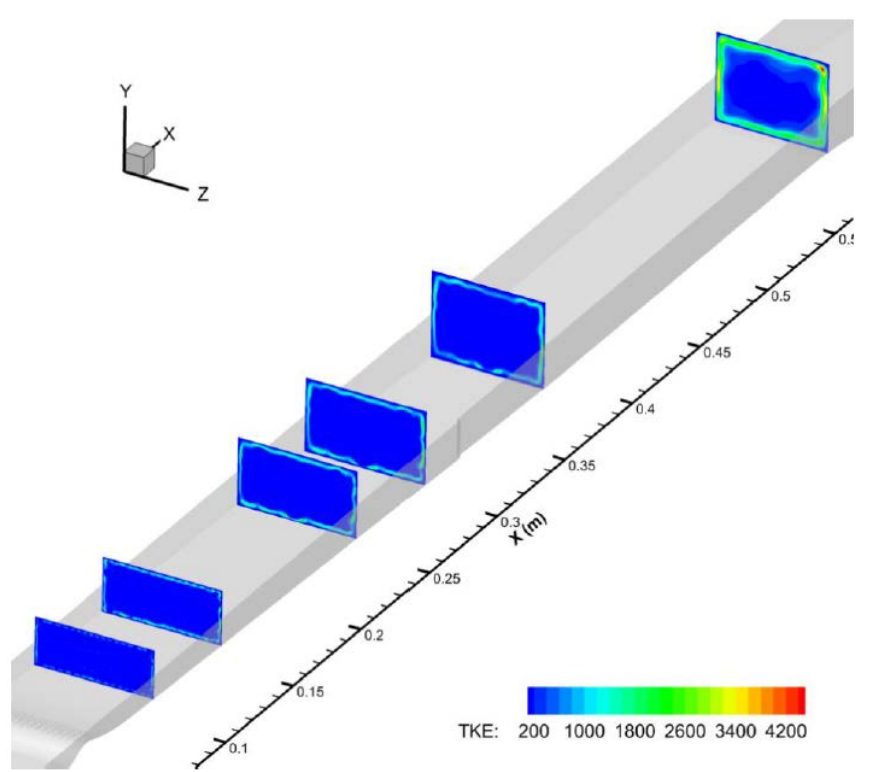

b. Mach number

Figure 16: Resolved-scale turbulence kinetic energy in the lasing cavity

Overall, the limited interaction between the core flow and boundary layers means that accurate modeling of the flow will be highly sensitive to the turbulence model's ability to capture boundary layer behavior and shock-boundary interaction. Additionally, because the bulk of the turbulence production occurs near the wall where the LES/RANS model transitions to RANS, this explains why the wall pressure prediction between the pure RANS and hybrid models is so similar.

\subsection{CONCLUSIONS}

Several hybrid LES/RANS and RANS simulations have been conducted for model COIL laser flow fields on meshes with different levels of isotropic resolution and under different back pressures. Adequate resolution of outer-layer turbulent eddies is of primary importance in ensuring reasonable success of the LES/RANS modeling strategy. Estimates of outer-layer turbulent length scales obtained from pre-cursor RANS simulations have been used to design large meshes that provide good resolution for capturing the transition to turbulence induced by the shock train. Wall-pressure predictions obtained by both LES and LES/RANS indicate reasonable agreement with experimental data, with the most notable discrepancy being the inability of either model to capture the rate of pressure increase experienced as the flow passes through the leading edge of the shock train. The LES/RANS model is capable of predicting shock-induced transition to turbulence as well as unsteadiness due to instability growth as the reactant jets enter and mix within the lasing cavity. Reactant mixing is due to laminar-flow effects and is performed efficiently by the jet-array configuration. Local separation regions induced by the shock train do not propagate very far into the mixing region, except possibly at the highest back pressure of 26 Torr (which was simulated on a mesh that did not contain the injection array). The effects of shock-train propagation on reactant mixing appear to be minor at 
lower back pressures (14.7 Torr and 22.8 Torr), indicating that the current COIL diffuser design might provide adequate isolation.

\subsection{CONNECTIONS}

Funding received under this grant has been used to support the Ph.D. studies of Ilya A. Zilberter.

\subsection{ACKNOWLEDGEMENTS}

This material is based on research supported by the Air Force Research Laboratory under agreement number FA9451-13-1-0262. The U.S. Government is authorized to reproduce and distribute reprints notwithstanding any copyright notation thereon. The views and conclusions contained herein are those of the authors and should not be interpreted as necessarily representing the official policies or endorsements, either expressed or implied, of the Air Force Research Laboratory or the U.S. Government. Computer time was provided by the DoD's High Performance Computing Modernization Program.

\subsection{REFERENCES}

[1] Piponniou, S., Dussauge, J.P., Debieve, J.F., and Dupont, P. “A Simple Model for LowFrequency Unsteadiness in Shock-Induced Separation”, Journal of Fluid Mechanics, Vol. 629, 2009, pp. 87-108.

[2] Gieseking, D. and Edwards, J.R. "Simulations of a Mach 3 Compression-Ramp Interaction using LES/RANS Models” AIAA Journal, Vol. 50, No. 10, 2012, pp. 2057-2068

[3] Noren, C., Ortiz, T., Wilkinson, M., Klennert, W., Madden, T., Chan, R., Decker, R., and Walter, R. "Experimental and Computational Investigation of a Converging-Diverging NozzleDiffuser with Cross Flow Injection”, AIAA Paper 2010-1156, Jan. 2010.

[4] Madden, T.J. and Decker, R.K. "Simulation of High Power Lasers" Proceedings of the 2010 DoD High Performance Computing Modernization Program User's Group Conference, Schaumburg, Il,, June, 2010

[5] Colella, P., and Woodward, P. R., "The Piecewise Parabolic Method (PPM) for GasDynamical Simulations,” Journal of Computational Physics, Vol. 54, 1984, pp. 174-201

[6] Edwards, J.R. “A Low-Diffusion Flux-Splitting Scheme for Navier-Stokes Calculations," Computers and Fluids, Vol. 26, No. 6, 1997, pp. 635-659.

[7] Ducros, F., Ferrand, V., Nicaud, F., Weber, C., Darracq, D., Gachareiu, C., Poinsot, T. "Large-Eddy Simulation of the Shock / Turbulence Interaction" Journal of Computational Physics, Vol. 152, No. 2., 1999, pp. 517-549.

[8] Gieseking, D.A., Choi, J.-I., Edwards, J.R., and Hassan, H.A. "Compressible Flow Simulations using a New LES/RANS Model” AIAA Journal, Vol. 49, No. 10, 2011, pp. 21942209.

[9] Zilberter, I.A. and Edwards, J.R. "Shock Train Formation in COIL Lasers", AIAA Paper 2014-2072, June, 2014.

Approved for public release; distribution unlimited. 


\section{LIST OF SYMBOLS, ABBREVIATIONS AND ACRYNOMS}

$\begin{array}{ll}\text { LES/RANS } & \text { Large-eddy Simulation/ Reynolds-averaged Navier-Stokes } \\ \text { COIL } & \text { Chemical Oxygen Iodine Laser } \\ \text { RANS } & \text { Reynolds-Averaged Navier-Stokes } \\ \text { NCSU } & \text { North Carolina State University } \\ \text { ILU } & \text { Incomplete Lower-Upper } \\ \text { LDFSS } & \text { Low Diffusion Flux-Splitting Scheme } \\ \text { LD-PPM } & \text { Low-Dissipation Piecewise Parabolic Method } \\ \text { PPM } & \text { Piecewise Parabolic Method } \\ \text { SST RANS } & \text { Shear Stress Transport RANS }\end{array}$

Approved for public release; distribution unlimited. 
DISTRIBUTION LIST

DTIC/OCP

8725 John J. Kingman Rd, Suite 0944

Ft Belvoir, VA 22060-6218 1 су

AFRL/RVIL

Kirtland AFB, NM 87117-5776 1 су

Carrie Noren

Official Record Copy

AFRL/RDLTS

1 cy

Approved for public release; distribution unlimited. 